\title{
Gestão da riqueza velha e criação de riqueza nova: uma crítica à Modern Money Theory (MMT) *
}

\author{
Luiz Gonzaga Belluzzo **,*** \\ Lício da Costa Raimundo ${ }^{* * * *}$ \\ Saulo Abouchedid ${ }^{* * * * *}$
}

\begin{abstract}
Resumo
A discussão sobre política monetária, a moeda e sua natureza voltou ao centro do debate econômico no Brasil e no mundo. No cerne do debate proposto estão questões centrais, como, por exemplo, a da impossibilidade de um governo soberano não honrar dívidas denominadas em sua própria moeda, proposição central da Modern Monetary Theory (MMT), além da colocação em dúvida do que foram, até pouco tempo atrás, pressupostos basilares da teoria econômica convencional, como por exemplo a imprescindibilidade de uma organização da política monetária em torno do estabelecimento de um Banco Central Independente que persiga metas de inflação. Nesse contexto, este artigo possui dois objetivos principais. Primeiro, busca-se identificar com maior precisão as molduras teóricas que sustentam duas visões distintas sobre o que é a moeda em uma economia capitalista plenamente desenvolvida. De um lado, a visão da moeda-mercadoria, que incorpora a construção teórica da economia política clássica; de outro, a moeda vista como uma instituição social, pertencente ao arcabouço teórico de matriz keynesiano-marxista. Segundo, busca-se compreender os principais pressupostos da MMT e seus pontos de convergência e divergência em relação às duas visões supracitadas. A partir da perspectiva keynesiano-marxista, concluise que não se sustentam as abordagens teóricas que tratam Estados e mercados como entes abstratos, que operam em cenários ideais, afastados das reais condições econômicas, sociais e políticas do momento presente, dentre as quais se destaca a MMT.
\end{abstract}

Palavras-chave: Moeda, MMT, Soberania.

\section{Abstract \\ Wealth management and new wealth creation: a critique of Modern Money Theory (MMT)}

The debate on monetary policy, currency and its nature has returned to the center of the economic debate in Brazil and in the world. At the heart of the proposed debate are central issues, such as, the impossibility of a sovereign government to not honor debts denominated in its own currency, the central proposition of Modern Monetary Theory (MMT), in addition to putting into doubt what were, until recently, basic assumptions of conventional economic theory, such as the indispensability of a monetary regime supported by an Independent Central Bank, that pursues inflation targets. In this context, this article has two main objectives. First, it seeks to identify more precisely the theoretical frameworks that support two different views on what currency is in a fully developed capitalist economy. On the one hand, the view of the commodity currency, which incorporates the theoretical construction of classical political economy; on the other, currency seen as a social institution, belonging to the Keynesian-Marxist theoretical framework. Second, it seeks to understand the main assumptions of MMT and its points of convergence and divergence in relation to the two views mentioned above. From the Keynesian-Marxist

\footnotetext{
* Artigo recebido em 11 de fevereiro de 2020 e aprovado em 23 de abril de 2020.

${ }^{* *}$ Professor Titular do Instituto de Economia da Universidade Estadual de Campinas (IE/Unicamp), Campinas, SP, Brasil. E-mail: belluzzop@ terra.com.br. ORCiD: https://orcid.org/0000-0002-8000-6538.

${ }^{* * * *}$ Professor das Faculdades de Campinas (Facamp), Campinas, SP, Brasil.

***** Professor de Economia Monetária das Faculdades de Campinas (Facamp), Campinas, SP, Brasil. E-mail: liciocr@gmail.com. ORCiD: https://orcid.org/0000-0001-8888-1321.

***** Professor de Economia Monetária das Faculdades de Campinas (Facamp), Campinas, SP, Brasil. E-mail: saulo.ab7@gmail.com. ORCiD: https://orcid.org/0000-0002-5914-4311.
} 
perspective, it is concluded that the theoretical approaches that treat states and markets as abstract entities, operating in ideal scenarios, far from the real economic, social and political conditions of the present moment, such as MMT, are not supported.

Keywords: Money, MMT, Sovereignty.

JEL E40, E42, E44.

\section{Introdução}

A discussão sobre política monetária, a moeda e sua natureza voltou ao centro do debate econômico no Brasil e no mundo a partir de recentes artigos publicados pelo economista André Lara Resende $^{1}$ e de livro recém-publicado por Blanchard e Summers (2019). No cerne do debate proposto estão questões centrais, como, por exemplo, a da impossibilidade de um governo soberano não honrar dívidas denominadas em sua própria moeda, proposição central da Modern Monetary Theory $(\mathrm{MMT})^{2}$, além da colocação em dúvida do que foram, até pouco tempo atrás, pressupostos basilares da teoria econômica convencional.

Com base na discussão supracitada, este artigo possui dois objetivos principais. Primeiro, busca-se identificar com maior precisão as molduras teóricas que sustentariam duas visões distintas sobre o que é a moeda em uma economia capitalista plenamente desenvolvida, estabelecendo de forma mais clara os campos teóricos do debate atual. De um lado, a visão da moeda-mercadoria, que incorpora a construção teórica da economia política clássica; de outro, a moeda vista como uma instituição social, resultado do conflito irredutível vigente em uma sociedade capitalista, pertencente ao arcabouço teórico de matriz keynesiano-marxista. Segundo, busca-se compreender os principais pressupostos da MMT e seus pontos de convergência e divergência em relação às duas visões supracitadas.

A partir desses objetivos, a primeira, segunda e terceira seção apresentam, respectivamente, a visão neoclássica da moeda-mercadoria; a visão keynesiana e marxista da moeda e a visão da moeda como criatura do Estado, apresentada pela MMT. Por fim, a quarta e a quinta seção analisam os principais limites e insuficiências da MMT como corrente teórica alternativa à teoria convencional após a eclosão da crise financeira global em 2008.

\section{A moeda-mercadoria}

A percepção da moeda como moeda-mercadoria tem por fundamento a existência de uma sociedade na qual o conflito é restrito à concorrência confinada no âmbito dos produtores independentes e que se dá basicamente em torno do mecanismo de aprimoramento da base técnica sobre a qual se apoia a coletividade. As diferenças de ganho de produtividade dos diversos produtores de bens de elevado grau de homogeneidade permitiriam circunscrever o conflito social ao âmbito técnico. Os agentes econômicos mais aptos, ou seja, mais produtivos, vicejariam ao passo que aqueles que não conseguissem acompanhar o ritmo do progresso técnico pereceriam. Desta forma, a sociedade se organizaria sobre uma base de contínuo ganho técnico que se alastra por toda a

(1) Lara Resende (2017).

(2) Wray (2015). 
coletividade na forma de menores preços, produtos de maior qualidade, novos bens e serviços, sempre no interesse do cada vez maior bem-estar social.

Não é, no entanto, da benevolência do padeiro ou do açougueiro que provém o pão e a carne. Nessa sociedade, a busca do interesse individual tem uma dupla ligação estrutural com as formas essenciais de organização social: por um lado, é a busca do maior interesse individual que tem como resultado a harmonia social e o progresso econômico. Ao buscar seu próprio interesse, cada um dos produtores independentes contribui para a ampliação do nível do progresso técnico geral, resultando em um incremento de bem-estar coletivo, nas formas apontadas. Uma sociedade mais rica e próspera, além de mais justa e harmônica, seria o resultado do pleno exercício da liberdade econômica desfrutada de cada um de seus membros.

Por outro lado, a possibilidade de que esta sociedade funcione continuamente gerando cada vez mais progresso social ancora-se na racionalidade que preside os atos isolados e independentes de cada um dos produtores individuais. É essa racionalidade, inata e comum a todos os homens, que resolve $a$ priori a questão da efetividade da troca e, antes até, da decisão de produção de um excedente voltado à troca. Certos de que encontrarão seres racionais quando se apresentarem no mercado para $o$ ato de troca, os indivíduos propõem-se a produzir excedentes que lhes permitirão maximizar seu próprio bem-estar e, como consequência, o bem-estar de toda a coletividade. Esse bem-estar é ampliado não apenas por força do acesso a bens e serviços de qualidades distintas daqueles produzidos por cada um dos produtores isolados, mas sobretudo porque ao se especializar na produção de um determinado bem, cada indivíduo obtém ganhos de produtividade que resultarão em menores preços e em maiores quantidades de bens obtidos em troca dos seus.

Ao final e ao cabo, toda a coletividade estará melhor porque cada um dos seus membros pôde (teve a liberdade para) buscar seu próprio interesse. A racionalidade inata, a liberdade de ação e de escolha e a possibilidade de ampla circulação de bens e serviços garantem que o resultado final seja a melhor e mais justa distribuição de riquezas a todos os participantes dessa coletividade.

Nessa sociedade, o Estado tem um papel decisivo: o de garantir a existência de um ambiente de liberdade para que cada indivíduo possa buscar sua máxima satisfação. Tal ambiente não pode, de forma alguma, limitar as liberdades de alguns em benefício da liberdade de outros, daí o papel central do Estado em combater qualquer formação monopólica. O exercício da força por parte do Estado se legitima, aqui, na medida em que ela funciona como um garantidor da liberdade individual.

Nesse tipo de conformação social, a moeda tem um papel meramente secundário. Ela pode, no máximo, servir como um elemento facilitador das trocas e, além disso, funcionar como unidade de conta e reserva de valor. Mas não há papel para a moeda como elo da relação social entre os produtores independentes. Estes já foram pré-conciliados pela ação decisiva de sua própria racionalidade, manifestada de forma espontânea mediante a liberdade garantida previamente pelo Estado. Se desse arranjo social fosse retirado esse véu monetário, nada mudaria em essência. Os indivíduos criariam suas próprias relações de troca e sua própria moeda a partir de seus hábitos pretéritos e dos custos de produção de seus bens e serviços. A moeda aqui não é mais que uma tecnologia social. Algo que nasce para auxiliar o processo de troca e para torná-lo mais produtivo e eficaz. 
Nesse tipo de percepção do arranjo econômico e social, um acréscimo ao estoque existente de moeda pode tranquilamente ser criado pelo Estado. A moeda adicional será aceita ou rejeitada na exata medida das necessidades dos negócios. Caso o Estado crie mais moeda que aquela necessária à circulação dos bens e serviços transacionados na sociedade, esta rejeitará tal excesso de moeda, manifestando-se tal rejeição pelo fenômeno inflacionário. Caso a quantidade de moeda criada pelo Estado esteja aquém das necessidades da troca, a própria sociedade tratará de ajustar sua quantidade à disponibilidade de bens e serviços fazendo com que seus preços caiam, num fenômeno deflacionário.

Dessa forma, não parece haver uma distinção sensível entre a variante teórica que imagina que a moeda entre em circulação porque ela é demandada pelas trocas e aquela que entende que ela é inserida por vontade única do Estado, como será visto à frente. Pensar a expansão da oferta monetária como sendo resultado único da vontade do soberano exige que se pense em uma sociedade na qual a moeda não contém, em si, o conflito social. Para a MMT, a moeda pode ser adicionada ou retirada de circulação na medida em que as obrigações tributárias assim o exigirem. A aceitação da moeda se faz por força da imposição dessas obrigações. A suspensão total ou parcial de tais obrigações resultaria em um excesso de moeda, rejeitada pela sociedade por não ter mais função.

\section{A moeda como um fato social total}

Em Marx e Keynes a moeda adquire outro estatuto. Aqui, a moeda é um fato social total ${ }^{3}$, no sentido de ser elemento central da organização capitalista. A moeda precede os atos dos produtores independentes, sendo sua racionalidade fator insuficiente para a ancoragem da organização social. Na sociedade capitalista vige a luta diária pela apropriação da riqueza, velha (já existente) e nova. Nessa luta encarniçada, os instrumentos voltados ao aumento da produtividade do trabalho não são as únicas armas da concorrência. Os mecanismos de poder se estendem a toda uma gama de opções, legais e nem tanto, voltadas a superar a concorrência na sanha acumulativa de riqueza. Nessa sociedade, riqueza é sinônimo de poder.

A luta social ganha uma dimensão decisiva: a dimensão monetária, que envolve o Estado e todos os agentes privados. Estes buscam simultaneamente corromper $e$ preservar a estabilidade do padrão monetário, em um movimento contraditório próprio do funcionamento de uma economia capitalista. Corromper, pois por um lado trata-se de apropriar-se da riqueza mesmo que à custa da ruptura do padrão monetário ${ }^{4}$. Preservar, pois o padrão monetário é o único critério de medida da riqueza já acumulada em circuitos prévios de acumulação. Tal ambivalência estaria no cerne da questão monetária, sendo mesmo sua característica mais expressiva.

Nesta sociedade, não há arranjo social harmônico e a justiça social não emerge do livre jogo das ações individuais dos produtores independentes em sua busca pela maximização de seu interesse individual. O que impera nesse arranjo social é a constante desarmonia, a permanente ruptura das

(3) Mauss (2007).

(4) Essa possível disrupção dar-se-ia, por exemplo, quando da ocorrência de fenômenos inflacionários ou hiperinflacionários que tornariam a moeda um padrão cada vez menos adequado para sua função de mediação do metabolismo econômico e social. Um ambiente institucional permissivo à livre expansão do crédito privado (com baixo ou nenhum controle público), por exemplo, em algum momento provavelmente condiziria a uma situação de ruptura do padrão monetário pela via da criação de um processo inflacionário crônico. 
condições pretéritas, a reiterada violência, fruto da tentativa constante e incansável de eliminar a concorrência. Longe de limitar-se aos padrões impostos pelas formas de desenvolvimento tecnológico, a violência da concorrência só encontra seus limites, ainda que provisórios, quando confrontada pela violência daquele que tem a legitimidade de propor o padrão monetário: o Estado.

A possibilidade de ruptura do padrão monetário, imposta pelo próprio jogo de forças atuantes na economia, impõe de forma permanente, por um lado, a busca da impossível, porém necessária, estabilidade do padrão de referência e de cálculo da riqueza social. De outro, tal possibilidade de ruptura exige a presença do Estado, que busca restituir as condições de acumulação, condições estas que se confundem com aquelas necessárias para que, no capitalismo, o próprio processo de reprodução social ocorra.

O Estado, muito mais que um simples ator que assiste ao drama social e econômico de uma posição exterior, é figura central da trama, na medida em que cabe a ele, em comum acordo com os proprietários da riqueza capitalista, a restauração das condições de organização social, que tem no padrão monetário sua peça central. Assim, o Estado, por um lado também sujeito às tentações que conduzem à ruptura do padrão monetário, busca equilibrar-se em um arranjo no qual seus mecanismos de poder estão limitados pelos desejos e impulsos dos proprietários dos meios de produção. Estes não permitem ao Estado expandir ilimitadamente a dívida pública, assim como, simultaneamente, o próprio Estado estabelece limites à ampliação considerada desmesurada das várias formas de moeda privada (crédito). Nesse jogo em que a estabilidade monetária está em permanente risco de ruptura, o Estado e o grande capital estabelecem, institucionalmente, regras de expansão monetária.

Muito diferente da estrutura da economia política clássica e neoclássica, a percepção da moeda como uma expressão de um feixe de contradições não admite a existência de uma gestão monetária e de dívida pública, por parte do banco central e do Tesouro Nacional, que não esteja de acordo com os impulsos e perspectivas do grande capital, nacional e estrangeiro. Este, busca moldar a gestão monetária de forma mais permissiva ou mais conservadora, de acordo com suas estratégias específicas e momentâneas de valorização do capital.

Sem poder escapar à contradição que está na base da organização capitalista, a gestão da moeda não conhece a noção de equilíbrio. O desequilíbrio é sua norma, na medida mesma do movimento das estruturas do sistema e de seus espasmos de criação e destruição de riqueza.

\section{Marx, Keynes e as dificuldades de desvalorização do capital fictício}

As relações entre a "economia real" e a economia monetário-financeira não são de exterioridade, mas nascem dos desdobramentos das formas assumidas pelo capital em seu movimento de expansão permanente. Nesse movimento estão inscritas a concentração e centralização do controle do capital líquido em instituições de grande porte e cada vez mais interdependentes. O circuito D-D' nasce das tendências centrais do regime do capital: um processo necessário e inexorável, porque a acumulação capitalista é acumulação de riqueza abstrata e, ao mesmo tempo, um movimento de abstração real que transfigura o dinheiro, a encarnação substantivada do valor e da riqueza, nas formas "desenvolvidas" do dinheiro de crédito, do capital a juros e do capital fictício (Marx, 1983). 
A propósito do dinheiro de crédito, Marx afirmou reiteradamente que o desenvolvimento (no sentido lógico-genético) do regime do capital reforça o caráter social da produção de mercadorias e esse avanço da "socialização capitalista" torna a conversibilidade do dinheiro de crédito no dinheiro mercadoria "uma aspiração disparatada'. Como já foi dito acima, para Marx o dinheiro - a forma geral do valor e expressão universal da riqueza - e somente ele, realiza a riqueza individual como riqueza social; é o dinheiro este objeto. Há quem confunda essa objetividade com a corporeidade metálica, mas, na construção de O Capital, a corporeidade metálica é apenas o passo "mercantil" para que a objetividade assuma a sua forma apropriada ao regime do capital plenamente constituído.

A existência social (do dinheiro) 'aparece' como um objeto, uma coisa, como mercadoria, junto aos elementos reais da riqueza social e, ao mesmo tempo, à margem deles. Quanto a produção funciona sem entorpecimentos, isto não é lembrado. O crédito que também é uma forma social da riqueza substitui o dinheiro (metálico) e usurpa o lugar que lhe correspondia. É a confiança no caráter social da produção que faz a forma dinheiro dos produtos como algo destinado a desaparecer, como algo puramente ideal, como mera representação... mas, tão logo estremeça o crédito, pretende-se que toda a riqueza real deve ser convertida em dinheiro (nas reservas-ouro), aspiração disparatada, mas que brota necessariamente do sistema mesmo (Marx, 1894 apud Belluzzo, 2013, p. 110).

O sistema que produz essa aspiração disparatada é a ilusão que nasce do jogo entre o caráter cada vez mais social da produção no regime do capital e a forma material do dinheiro destinada a desaparecer. A conversibilidade do dinheiro de crédito na moeda metálica já é uma relíquia bárbara diante da evolução do sistema de crédito e da desmaterialização do dinheiro, algo puramente ideal, fundado na confiança.

A transfiguração do sistema monetário suscitado pela generalização do crédito e da moedacrédito tornou a valorização do capital cada vez mais dependente das instituições que administram a riqueza socializada e, portanto, das relações entre elas e as ações dos Bancos Centrais e dos Tesouros Nacionais. A estabilidade da economia monetária depende das complexas relações entre os fundos coletivos administrados pelos comitês privados de avaliação do crédito e da riqueza mobiliária e a capacidade do Estado, mediante as decisões do Banco Central, de orientar as expectativas dos agentes privados empenhados na liça da acumulação de riqueza abstrata. Esses trabalhos do Estado são executados pela política monetária do Banco Central em conjunto com a gestão da dívida pública pelo Tesouro. No regime de moeda denominada pelo Estado e emitida pelo sistema bancário, a estabilidade da economia não pode ser garantida, como imaginam os partidários do free banking, pelos critérios privados de maximização dos ganhos, como o demonstra à saciedade a experiência histórica dos sistemas bancários desregulamentados e, na prática, desprovidos de autoridade central pública.

A crise de 2007 desvelou as relações carnais entre o dinheiro, as finanças públicas e os mercados financeiros privados no capitalismo contemporâneo. O moderno sistema de crédito - aí incluído o Banco Central - opera como o espaço em que se explicita a natureza ambígua do dinheiro na economia capitalista: bem público, ou seja, forma social da riqueza e bem privado, objeto do enriquecimento privado (Aglietta; Orleán, 1982). Os bancos (e, hoje, os demais intermediários financeiros que se abastecem nos mercados monetários) são provedores da infraestrutura do mercado, na medida em que definem as normas de acesso à liquidez, ao crédito e administram o sistema de 
pagamentos. Tais normas impõem constrangimentos às condições de produção e de concorrência das empresas. Na condição de gestores públicos e privados da forma geral da riqueza, os bancos cuidam de administrar o estado da liquidez e do crédito de acordo com a maior ou menor confiança na possibilidade das empresas e dos governos de controlarem seus balanços.

A "financeirização" não contrapõe imediatamente e diretamente os interesses dos bancos e das instituições financeiras aos interesses da classe operária e demais trabalhadores e assalariados dependentes. No capitalismo plenamente investido em todas as suas formas, a contradição está abrigada nas próprias relações entre as formas de posse da riqueza. No movimento da acumulação, ao longo do processo de expansão do valor, ampliam-se os estoques de ativos reais e financeiros, ao mesmo tempo em que o progresso tecnológico "desvaloriza" continuadamente a força de trabalho e o estoque de capital produtivo existente.

A dominância da forma financeira, ao contrário do que pretende a vulgata de esquerda, não denuncia o "descolamento" da valorização fictícia dos estoques de riqueza já produzida em relação à geração de valor na esfera produtiva, senão acusa o desenvolvimento das formas avançadas, isto é, mais socializadas e contraditórias de geração do valor e de avaliação da riqueza.

Dessa forma, mostra-se cada vez mais imperioso que o Estado impeça a brusca desvalorização da riqueza acumulada na forma de direitos sobre a riqueza futura. Quando tal forma de riqueza captura todos os grupos sociais, direta ou indiretamente, cabe ao Estado capitalista garantir a sustentação dos níveis de valor obtidos pelos títulos de dívida, pública e privada, e pelos títulos de propriedade negociados em mercados secundários, organizados ou não. Sustentar os níveis de valorização da riqueza velha existente, evitando sua súbita desvalorização e oferecendo uma sobrevida à atual forma de organização da economia capitalista, passa a ser o papel central do Estado. Para tanto, nenhuma restrição prévia de gastos pode se impor a este como um fator limitante de sua ação.

\section{A moeda como criatura do Estado: a MMT e seus desdobramentos}

Conforme Wray (2015), a Modern Money Theory (MMT) se inseriu no debate monetário a partir de pressupostos teóricos de um conjunto de autores - John Maynard Keynes, Karl Marx, Hyman Minsky, Abba Lerner, entre outros. Para esta corrente teórica, a moeda é criatura do Estado soberano, que impõe a aceitação (e, consequentemente, a demanda) desse reconhecimento de dívida (IOU em inglês) por meio da denominação dos impostos e outras taxas governamentais na moeda em questão. Assim, a gênese da moeda se relaciona com o poder do Estado em determinar a unidade de conta de seus impostos.

Essa concepção de moeda, no entanto, não é uma contribuição da MMT à teoria monetária. O lema "taxes drive money" já tinha sido defendido por dois autores ao menos. Knapp (1905) - por meio de sua State Theory of Money - sugere que o Estado define a moeda legalmente e por meio da cobrança de impostos, estabelecendo uma doutrina conhecida como cartalista. Ademais, Ruml (1946), conselheiro do New Deal e presidente do Federal Reserve de Nova York, questionou a necessidade de impostos para financiar os gastos do governo, em razão da melhora na gestão da 
liquidez por parte dos bancos centrais e da eliminação da conversibilidade da moeda em ouro ${ }^{5}$. Neste contexto, os impostos teriam função essencialmente redistributiva e estariam conectados, portanto a determinadas políticas públicas ${ }^{6}$. Wray (2015, cap. 5) também incorpora essa visão, ressaltando que, além da função primordial de impor a moeda estatal, a arrecadação tributária se destina principalmente à estabilização da demanda agregada - evitando expansões desenfreadas e, consequentemente, processos inflacionários - e à redistribuição da riqueza e da renda, por meio de um sistema tributário progressivo que combata, por exemplo, o rentismo e os salários elevados dos executivos das grandes corporações.

Ademais, Wray (2015) refuta o caráter essencialmente convencional da moeda, enfatizado por Aglietta e Orleán (1982). Conforme o autor americano, o poder do Estado na definição da unidade de conta - ou de escrever o dicionário, nas palavras de Keynes (1930) - precede a aceitação do público do símbolo monetário:

I'd be embarrased to write that in my own textbook, or to try to convince a skeptical student that the only thing backing money is the "greater fool" or "hot potato" theory of money (Wray, 2015).

A concepção de moeda relatada acima gera diversas implicações na relação entre o Estado e os detentores de riqueza privada. A principal delas se relaciona com a capacidade de expansão dos gastos públicos: considerando que os impostos são apenas instrumentos que legitimam a moeda criada pelo Estado, não há razão para supor que a arrecadação tributária financie os gastos do governo. O dispêndio público, portanto, não sofre restrições financeiras por parte dos impostos ou de títulos públicos, fato que impossibilita a insolvência do Estado soberano (Wray, 2015; Bell, 1998).

Neste contexto, o reconhecimento de dívida (IOU) emitido pelo Estado está no topo da pirâmide monetária, organizada conforme a liquidez de cada ativo. Logo abaixo se encontram os IOU's (denominados na moeda estatal) emitidos pelos bancos comerciais, que possuem contas por sua vez nos bancos centrais. Tais IOU's bancários são trocados ao par pelo IOU governamental, ou seja, são compensados e liquidados pela moeda estatal nos mercados interbancários. A posição inferior na pirâmide refere-se à possibilidade de corridas bancárias (desconfiança em relação ao sistema bancário), aumentando a demanda pela moeda estatal. Assim, a organização do sistema monetário depende da capacidade de o Banco Central garantir em última instância a paridade entre moeda bancária e moeda estatal. A partir dessa garantia, os demais IOU's privados (emitidos por instituições bancárias e empresas não financeiras) se encontram na base da pirâmide. A liquidez desses papéis varia conforme a facilidade e rapidez de conversão para os IOU's bancários (Wray, 2015).

Conforme a MMT, a relação entre Banco Central, Tesouro e setor privado não impõe limitações tanto ao gasto público quanto à condução da política monetária. O Banco Central sempre consegue exercer sua função de emprestador de última instância, ou seja, esta última não é sujeita a contestações por parte das instituições que compõem o sistema financeiro. Ademais, restrições na relação entre Banco Central e Tesouro - como, por exemplo, a proibição da compra direta de títulos do Tesouro pelo Banco Central -, bem como a forma pela qual o gasto público é realizado (por meio

(5) "The necessity for a government to tax in order to maintain both its independence and its solvency is true for state and local governments, but it is not true for a national government".

(6) Sobre a função redistributiva dos impostos ver Wray (2015, cap. 6). 
de reservas ou títulos públicos) não afetam a proposição "taxes drives money". A única diferença se dá na composição da riqueza do setor privado, que terá mais reservas ou títulos conforme o financiamento do déficit governamental e a gestão de liquidez do Banco Central (dada a meta da taxa de juros básica).

Nesse contexto, a emissão dos títulos do Tesouro é realizada de maneira voluntária: é uma alternativa atrativa às reservas por oferecer alguma rentabilidade. Assim, pressões advindas de investidores estrangeiros, por exemplo, não comprometem a capacidade de financiamento do Tesouro, tampouco pressionam a taxa de juros de curto prazo, controlada pelo Banco Central:

Government can always "afford" large keystrokes, but markets cannot force the government hand because it can simply stop selling bonds and thereby let markets accumulate reserves instead.

Ademais, a possível desvalorização cambial causada pelas vendas dos títulos públicos pelos investidores estrangeiros não deve ser contida pela autoridade monetária, já que os desajustes na conta financeira causados pela saída de investimento em carteira seriam ajustados pela melhora na balança comercial e, consequentemente, no saldo de transações correntes (Wray, 2015, p. 121).

Há, no entanto, na abordagem de Wray, duas possíveis limitações ao aumento do gasto público. A primeira refere-se aos países que adotam regimes de câmbio administrados. O compromisso de conversão de uma determinada moeda doméstica em uma moeda estrangeira pode limitar os gastos públicos - e estimular políticas de austeridade -, se houver, por exemplo, ameaça de desvalorização cambial. Dessa forma, o regime de câmbio flutuante é condição indispensável para a autonomia de política monetária e fiscal ${ }^{7}$ e, portanto, para que os pressupostos da MMT sejam satisfeitos (ver Prates, 2017).

A segunda limitação refere-se à relação entre a carga tributária e os gastos públicos (em proporção ao PIB). Embora os gastos públicos precedam o pagamento de impostos - já que os agentes necessitam da moeda doméstica para realizar o pagamento das suas obrigações -, o aumento dos gastos numa proporção maior que a carga tributária pode levar a um aumento indesejado no nível de preços. Neste cenário, conforme Wray (2015, p. 53, tradução dos autores), "os vendedores aceitariam mais moeda doméstica somente mediante aumento dos preços, já que teriam todo o dinheiro que

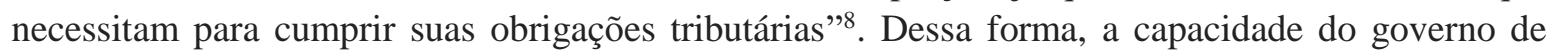
impor uma determinada carga tributária pode limitar o volume de gasto público (Wray, 2015, p. 53).

Embora defendam a ausência de restrição financeira para o gasto público, os teóricos da MMT não recomendam que o governo sempre deva gastar. Há diversos fatores que tornam o dispêndio governamental indesejável, tais como a inflação, pressões excessivas sobre a taxa de câmbio e escassez de recursos reais para o setor privado (Wray, 2015, p. 194). Dessa forma, a ação do Estado, por meio das políticas monetária e fiscal, deve ser funcional, ou seja, conforme um propósito público, conceito amplo, que abrange não apenas um objetivo econômico (busca do pleno emprego, por exemplo), mas também objetivos sociais, culturais, dentre outros. Essa ideia é inspirada

(7) Essa conclusão se insere na lógica da trindade impossível, elaborada por Mundell (1963), na qual o regime de câmbio flutuante assegura a autonomia de política monetária e o ajuste no balanço de pagamentos.

(8) Aqui Wray parece mais do que flertar com a Teoria Quantitativa da Moeda. 
na proposta de Abba Lerner das "finanças funcionais", que se pauta essencialmente na busca do pleno emprego, por meio da expansão dos gastos públicos e redução da taxa de juros.

A adoção do propósito das finanças funcionais pela MMT tem como principal desdobramento a ideia do Estado empregador de última instância - Job Guarantee $(J G)$ em inglês. O principal ponto dessa proposta, pensada pela primeira vez nos anos 1930, é estender a função de emprestador de última instância do Banco Central - que provê reservas para qualquer banco com dificuldades de obtê-las no mercado monetário - ao Tesouro, que teria a missão de prover trabalho ao desempregado involuntário. De acordo com este programa, o Estado seria responsável pelo financiamento de um programa universal de empregos em diversas áreas do setor de serviços (ou trabalho de cuidados), inclusive o meio ambiente (Wray, 2015; Henwood, 2019).

Ademais, a remuneração seria baseada em um salário por hora (definido pelo Congresso) e um pacote de benefícios. O salário-base estabelecido funcionaria como um piso para o setor privado, sendo uma espécie de "salário mínimo efetivo". Uma das principais vantagens do piso salarial é a sua função de estabilizador automático. Ou seja, durante a crise o "colchão" de trabalhadores sob a proteção do programa aumenta, evitando uma queda expressiva dos salários e, portanto, uma possível trajetória deflacionária. Por outro lado, nos momentos de bonança, os riscos de uma elevação salarial são contidos pela possibilidade de se demandar trabalhadores do programa JG a um custo previamente definido pelo Estado. Dessa forma, a contenção de variações expressivas do custo de produção limita o impacto do programa sobre o nível de preços (Wray, 2015).

\section{Os impasses do presente: as soluções da MMT são suficientes?}

Em seu mais recente livro, Blanchard e Summers (2019) se debatem em busca de novas certezas que possam ancorar a política econômica no presente. Cientes dos estragos causados pela crise de 2008 ao aparato teórico novo-keynesiano, os autores se perguntam sobre o que sobrou de seus fundamentos teóricos e que ainda possa ser utilizado para informar as práticas cotidianas da política econômica. Esta, ao que parece, estaria navegando no escuro.

Blanchard e Summers admitem o momento delicado vivido pelos gestores de política econômica. Os limites estreitos atingidos pelos gestores de política monetária, dados os limites impostos pelo zero lowerbound, os levam a assumira necessidade de buscar novas estratégias para conferir mais margem de manobra à política monetária ${ }^{9}$, assim como retomar a política fiscal como uma ferramenta importante de estabilização.

Esse mesmo assombro orienta a busca de Lara Resende (2017) no Brasil. Menos disposto a abrir mão de todas as suas crenças anteriores, o autor brasileiro abraça a MMT sem vacilar. Esta funcionaria como uma solução mágica, tão ao gosto dos antigos adeptos das certezas estabelecidas pela construção teórica tributária da economia política clássica. À dificuldade de admitir a inexistência de soluções de equilíbrio em uma economia capitalista, o autor contrapõe a possibilidade teórica defendida pela MMT de que o Estado Nacional passe a ampliar a emissão de dívida pública (e, por conseguinte, de emissão monetária) por força de sua única e exclusiva vontade. Sem nenhum

(9) Via a introdução de um sistema de metas para níveis de preços no lugar do sistema de metas de inflação (Bernanke, 2019.) ou mesmo via o estabelecimento de um sistema de metas para o PIB nominal no lugar do sistema de metas de inflação. 
conflito $^{10}$, o Estado resolveria todos os problemas de uma economia que insiste em não crescer: expandir o gasto público baseado no crescimento da dívida pública e, ao mesmo tempo, abrir "espaço fiscal" (Wray, 2015) para o gasto privado, administrando as eventuais pressões inflacionárias via eliminação do excesso de moeda pela via tributária.

As abordagens de Wray, Lara Resende e Blanchard e Summers partilham de pelo menos um ponto em comum: todas confessam seu extremo desassossego com o momento teórico vivido contemporaneamente pela macroeconomia. Mas todos eles, também, parecem incapazes de abandonar as estruturas de análise própria à economia política clássica. A "migração" de Lara Resende tem a aparência de ser a mais ousada, mas, no fundo, o autor pouco se move. Falta-lhe, em essência, um conceito mais apropriado de soberania.

Para Lara Resende e os teóricos da MMT, a soberania do Estado é algo garantido a priori. Além disso, trata-se de um atributo perene, não sujeito a contestações. Ao mercado (ou à sociedade, que em suas abordagens são sinônimos), resta um papel passivo perante o Estado. Caso o Estado decida gastar mais, via ampliação do estoque de dívida pública colocada junto ao mercado, este pode fazê-lo sem grandes problemas, afinal taxes drive money. Conforme observado na seção anterior, basta ao Estado, antes, ampliar as obrigações tributárias da sociedade via aumento de impostos. Isso seria suficiente para que se aceite, por parte do público, uma ampliação do estoque de dívida pública e, consequentemente, do estoque de moeda em circulação.

Se, no entanto, o conceito de soberania for destacado, a lógica de sua construção teórica fica em apuros. Caso se entenda que soberania é algo que emerge da sociedade e da qual o Estado está investido, e caso se compreenda que existem graus de soberania, toda a racionalidade básica do argumento de Wray e Lara Resende (e da própria MMT como um todo) fica comprometida. O Estado não é soberano apenas por ser o Estado. O Estado é soberano porque tem o poder de instituir um estado de exceção. Ou seja, a soberania em grau máximo se expressa naquele que tem o poder de suspender as regras instituídas pela sociedade, a qualquer momento e à sua única e exclusiva vontade.

No entanto, da perspectiva do padrão monetário, a grande maioria dos Estados Nacionais já não goza de tal prerrogativa hoje. O poder de sanção dos mercados financeiros nacionais e internacionais é muito superior à capacidade de determinação unilateral de boa parte dos Estados no que se refere a decisões relativas à gestão de dívida pública e de política econômica. Se há um soberano, hoje, este é muito mais o conjunto dos mercados financeiros, consubstanciados nos bancos e demais investidores institucionais, do que o Estado Nacional.

Dessa perspectiva, não se sustentam as abordagens teóricas que tratam Estados e mercados como entes abstratos, que operam em cenários ideais, afastados das reais condições econômicas, sociais e políticas do momento presente, dentre as quais se destaca a MMT. O mero cálculo capitalista, guiado por instinto para a máxima valorização à menor taxa de risco possível, induz à tomada de posições de segurança em momentos de elevada incerteza - algo que já faz nesse momento, por exemplo, os prêmios pagos pelos papéis públicos de mais longo prazo dos países centrais recuarem para patamares negativos em termos nominais. Neste contexto de instabilidade, a ação do Estado está

(10) "Através da fantasia do dinheiro sem esforço, a um pressionar de teclas de distância, todas essas relações de necessidade e de poder supostamente seriam varridas para longe" (Henwood, 2019). 
condicionada, primordialmente, às inquietudes dos agentes privados, que buscam, ao invés da expansão, a manutenção da sua riqueza. Assim, a insistência em não criar riqueza nova parece ancorada no medo de desvalorização da riqueza velha.

Ambas as abordagens (de Wray e Resende) parecem perder o essencial do momento presente do capitalismo: a necessidade de restaurar as condições para que o gasto privado obedeça a uma lógica coletiva de restauração das condições de convívio social. Programas como o Job Guarantee, relatado na seção anterior, são opções válidas de orientação do gasto público e geração de emprego, porém pecam na ideia de cooperação junto ao setor privado. Conforme nos lembra Henwood (2019) - ao resgatar o ensaio clássico de Kalecki (1977) - a garantia de pleno emprego pelo Estado afeta profundamente o poder de barganha do capitalista em relação ao trabalhador (representado pelos sindicatos). A ausência do temor do desemprego poderia aumentar o poder dos sindicatos na negociação dos salários e, consequentemente, afetar o poder de monopólio da classe capitalista. Tais implicações conflituosas sobre a relação entre trabalhadores e capitalistas não são endereçadas pela MMT. Há, portanto, uma dimensão política do princípio da demanda efetiva que pode dificultar a cooperação entre o Estado e o setor privado na busca do pleno emprego.

Destaca-se, por fim, a subavaliação, por parte da MMT, dos impactos do Sistema Monetário e Financeiro Internacional (SMFI) sobre a autonomia de política macroeconômica (Verganhini; De Conti, 2017; Prates, 2017). A adesão de Wray (2015) ao trilema de Mundell (1968) desconsidera as assimetrias do SMFI - explicitadas nos diferentes prêmios de liquidez das moedas domésticas no plano internacional e na subordinação dos mercados financeiros periféricos às decisões dos investidores globais - e seus efeitos deletérios sobre o movimento das taxas de juros e de câmbio, num contexto de abertura financeira (Prates, 2002; De Conti, 2011). Países periféricos, que emitem moedas com baixos prêmios de liquidez no plano internacional e que estão sujeitos aos ditames das finanças globais, estão mais sujeitos à volatilidade dos preços-chave.

A volatilidade da taxa de câmbio, por sua vez, é indesejada nos países que adotam o regime de câmbio flutuante e de metas de inflação, resultando em restrições na condução e nos objetivos da política monetária e cambial. As limitações na ação da autoridade monetária contradizem, portanto, as implicações da MMT para uma economia aberta, que entende que países que adotassem um regime de câmbio flutuante não gerariam limitações à ação do Estado, por meio da política fiscal ou monetária (Prates, 2017). Ao contrário do previsto por Wray (2015), além da restrição à autonomia de política econômica, a adoção de um regime de flutuação pura pode levar a instabilidades no balanço de pagamentos e, no limite, a crises monetárias - se considerarmos os possíveis impactos do câmbio à estabilidade de preços.

\section{Considerações finais}

A análise da gênese do dinheiro sob as lentes de diferentes escolas da teoria monetária nos fornece diferentes visões sobre os dilemas de política econômica ou, numa dimensão mais abstrata, sobre as relações entre o Estado e os proprietários privados de riqueza. Na teoria neoclássica, de inspiração walrasiana, a moeda não representa o elo da relação social entre os proprietários privados de riqueza, já que os interesses desses últimos estão pré-reconciliados por sua ação racional maximizadora. Dessa forma, cabe ao Estado criar moeda conforme as necessidades dos negócios, já 
que a gestão monetária ativa e discricionária não provocaria efeito algum na economia real no longo prazo.

Essa visão se contrapõe à lógica keynesiana e marxista, na qual o dinheiro é, conforme Belluzzo e Galípolo (2019, p. 121), “(...) fundamento das relações entre os produtores independentes e, por outro lado, o único critério quantitativo admissível para a avaliação do enriquecimento privado". Nesse contexto, a socialização dos indivíduos privados e a institucionalização da relação entre os proprietários de riqueza se dão por meio do dinheiro. Cabe ao Estado estabelecer a ordem monetária, a fim de organizar a luta encarniçada pela riqueza. No entanto, considerando que a ordem monetária se funda numa convenção - sujeita, portanto, a contestações dos agentes privados - a soberania monetária do Estado pode ser posta à prova a qualquer momento pelos proprietários privados de riqueza.

A crise financeira global de 2008 explicitou a ineficácia da política econômica fundada na tradição neoclássica e gerou reações diversas, das quais se destacam as críticas e recomendações de Blanchard e Summers (2019) e as propostas da MMT, capitaneadas, dentre outros autores, por Wray (2015). Embora pertençam a escolas diferentes da teoria monetária, tais visões possuem um elemento em comum: a suposição do pleno controle da gestão monetária e tributária por parte do Estado, assim como a inexistência de limites para seu endividamento. Nesse contexto, as críticas de tais autores estão centradas apenas na ampliação do gasto do Estado, desconsiderando os constrangimentos que os proprietários privados de riqueza impõem sobre a ação Estatal no exercício da busca pela valorização de suas riquezas.

No entanto, qualquer tentativa bem-sucedida de restaurar as condições do cálculo capitalista e de seu ímpeto investidor parece requerer uma mudança política profunda que restabeleça a presença do Estado como demandante de última instância e como articulador da maquinaria capitalista, sobretudo da decisão de investir, a exemplo de períodos de profundas crises como as assistidas nos anos 30 e durante as duas Grandes Guerras do Século XX.

A alternativa a esse controle público das decisões fundamentais de reprodução social nos moldes capitalistas remete à dissolução das condições de organização da sociedade nos moldes capitalistas, posto envolver uma brutal desvalorização da riqueza velha e a consequente destruição das relações de propriedade, já vistas em momentos anteriores da história. Nesses momentos, em vez da tão esperada (por alguns) reunião das condições de superação do capitalismo, o que se viu foi a emergência de regimes de exceção que trataram de impor uma nova ordem, regressiva e pautada, muito mais que na contradição capitalista, na arbitrariedade mais abjeta.

\section{Referências bibliográficas}

AGLIETTA, M.; ORLEÁN, A. A violência da moeda. São Paulo: Brasiliense, 1982. Introdução à segunda edição.

BELL, S. Can taxes and bonds finance government spending? Reserve accounting and government finance. In: The Third Annual Post-Graduate Economics Conference: Conference Papers, Leeds University Business School, 1998.

BELLUZZO, L. G. O capital e suas metamorfoses. São Paulo: Editora Unesp, 2013. 
Luiz Gonzaga Belluzzo, Lício da Costa Raimundo, Saulo Abouchedid

BELlUZZO, L. G.; GALÍPOLO, G. A escassez na abundância capitalista. São Paulo: Editora Contracorrente, 2019.

BLANCHARD, O.; SUMMERS, L. Revolution or evolution? Rethinking macroeconomic policy after the great recession. Cambridge, Massachusetts: MIT Press, 2019.

CONTI, B. M. D. Políticas cambial e monetária: os dilemas enfrentados por países emissores de moedas periféricas. Tese (Doutorado)-Instituto de Economia, Unicamp, 2011.

HENWOOD. A teoria monetária moderna não está ajudando. Jacobin Brasil, 25 jun. 2019. Disponível em: https://jacobin.com.br/2019/06/a-teoria-monetaria-moderna-nao-estaajudando/?fbclid=IwAR1fgfB1dfrZnZUfPNzROZ7vGQcvKN51uTVICjERWMvLv1MAUhFYBO 5_rMs. Acesso em: 25 nov. 2019.

LARA RESENDE, A. Juros, moeda e ortodoxia: teorias monetárias e controvérsias políticas. São Paulo: Editora Portfolio, 2017.

KALECKI, M. Os aspectos políticos do pleno emprego. In: KALECKI, M. Crescimento e ciclo das economias capitalistas: ensaios selecionados e traduzidos por Jorge Miglioli. São Paulo: Hucitec, 1977.

KEYNES, J. M. (1930). The treatise on money. Cambridge: Cambridge University Press, 2013. v. I e II.

KEYNES, J. M. (1936). A teoria geral do emprego, do juros e da renda. São Paulo: Editora Abril Cultural, 1983.

KNAPP, G. F. (1905). The state theory of money. New York: Augustus M. Kelley, 1973.

MARX, K. (1894). O capital: crítica da economia política. São Paulo: Nova Cultural, 1988. (Os Economistas). Livro terceiro. 1983.

MAUSS, M. Essai sur le don. Forme et raison de l'échange dans les sociétés archaïques. Paris: PUF, 2007.

MUNDELL, R. A. Capital mobility and stabilization policy under fixed and flexible exchange rates. The Canadian Journal of Economics and Political Science, v. 29, n. 4, p. 475-485, 1963.

PRATES, D. M. Crises financeiras dos países "emergentes": uma interpretação heterodoxa. Tese (Doutorado)-Instituto de Economia, Unicamp, 2002.

PRATES, D. M. Monetary sovereignty, currency hierarchy and policy space: a post-Keynesian approach. Campinas: Unicamp. IE, set. 2017. (Texto para Discussão, n. 315).

RUML, B. Taxes for revenue are obsolete. American Affairs, v. 8, n. 1, p. 35-39, 1946.

VERGANHINI, R.; DE CONTI, B. Modern Monetary Theory: a criticism from the periphery. Brazilian Keynesian Review, v. 3, n. 2, p. 16-31, 2018.

WRAY, R. Modern Monetary Theory. A primer on macroeconomics for sovereing monetary systems. 2. ed. New York: Palgrave Macmillian, 2015. 